\title{
Study on the Impact of Pension Institutions Needs and Measures--Case in Hangzhou
}

\author{
Tian-Zhou REN ${ }^{1}$, Dai FU 2, and Yuan LIN 1 \\ ${ }^{1}$ Zhejiang University of Technology, Hangzhou, China \\ ${ }^{2}$ Zhejiang Financial College, Hangzhou, China \\ ${ }^{1}$ rentianzhou@zjut.edu.cn
}

Keywords: Pension Institutions; Pension Willingness and Demand; Measures

\begin{abstract}
The aging population in Hangzhou is becoming larger and larger, and the old-age pension institutions are becoming an important supplement to the elderly. In May 2016, the results of the group's survey on the willingness and demand of the elderly in Hangzhou showed that the willingness of the elderly to stay in the pension institutions was influenced by factors such as education level, marital status, housing situation and household income. From the field survey, the number of pension institutions in Hangzhou is not enough, the development imbalance, lack of specialized personnel and facilities. We hope that in the pension Institutions reform and improve the process, taking into account the actual needs of the elderly.
\end{abstract}

\section{Introduction}

It is generally believed that if the population over 60 years more than $10 \%$ or the population over 65 more than $7 \%$, the region is called an aging society. China entered the aging society in 1999, according to the National Bureau of Statistics released the "2015 National 1\% Population Sampling Survey Main Data Bulletin" shows that, in 2015 China's population aged 60 and above accounted for $16.15 \%$, compared to the Sixth National Census in 2010 an increase of 2.89 percentage points. It is predicted that by 2020, the number of elderly population in China will reach 255 million, accounting for $17.8 \%$ of the total population; to 2053 the elderly population reached a peak of 487 million, accounting for $34.9 \%$. Such a large group of old age to the pension, medical, social services has brought great pressure, how to solve the aging population pension problem has become an increasingly important issue of people's livelihood.

In the early 90s of last century, Hangzhou has become an aging city, is one of the earliest aging city. Into the 21st century, elderly population in Hangzhou has become a huge group. Especially during the "12th Five-Year period", the city's elderly population is increasing rapidly. The total population of the elderly over 60 years of age increased from 1.168 million at the end of 2010 to 150.90 million at the end of 2015 . The proportion of the elderly population to the total population increased from $16.96 \%$ in 2010 to $20.86 \%$ at the end of 2015 , thus on average one is the elderly of 5 people. During the "12th Five-Year period", the total population growth rate in Hangzhou was 5\%, while the growth rate of the elderly population was $29.11 \%$, and the growth rate of the elderly population was significantly faster than that of the total population. With the improvement of housing conditions in Hangzhou, lifestyle changes and population movements more and more frequent, the elderly do not living with their children has become increasingly common, even in rural areas. When the size of the family continues to shrink, the demand for services such as "empty nest", age and sick people for medical care, nursing care, life care and psychological counseling will grow rapidly, relying solely on family or community services is far from enough. What are the factors that will affect their willingness to stay in pension institutions, how to stay, and the reasons for their actual stay? The answers to these questions will directly provide a basis for decision-making on government and social development agencies for pension services.

The research group conducted a one-to-one random sample questionnaire survey of the elderly aged 60 years and above in the main urban area of Hangzhou from April to June in 2006, and 
distributed 640 copies of the questionnaire, and 635 were recovered, of which 624 were valid questionnaires. We make a quantitative analysis of the factors that affect the aged for the elderly, with a view to making a number of recommendations on the development of China's pension institutions.

\section{Results and Analysis}

\section{The Willingness of the Elderly to Stay in Pension Institutions}

\section{The Willingness to Stay in Pension Institutions is Low}

In this survey, when asked about "Which method do you choose to support the aged? ", only 97 people choose "stay in pension institutions", accounting for $15.5 \%$ of the total sample. The elderly choose "family pension" the most, there are 407 people, accounting for $65.2 \%$. That most of the elderly want to enjoy at home.

\section{The Main Consideration is the Quality of Service}

Among the 97 elderly people who chose "stay in pension institutions ", 43.3\% of the elderly are most concerned about the quality of service of the pension institutions. Followed by the price, with $36.1 \%$ of the elderly choosing. $17.5 \%$ of the elderly are more concerned about whether the pension institutions for the public. However the size of the pension institutions and geographical location is almost no concern for the elderly.

\section{Affordable Price is Low}

When asked, "If you are admitted / have been admitted to the pension agency, what the affordable price you can accept", most of the elderly choose $¥ 2000-4000$ per month $(59.8 \%)$ and $¥ 2000$ per month $(38.1 \%)$.

\section{The Influencing Factors of the Pension Institutions}

Whether or not the elderly have chosen the pension institutions will be affected by a number of factors, we introduce a binary logistic regression model to analyze this problem. In this regression analysis, whether the elderly are willing to stay in pension institutions as dependent variable, that choose the pension agency is 1 , the other is 0 . The age, sex, education, health status, marital status, children, living conditions, family relationships, family income, children's visit, etc. as the dependent variables. In this regression analysis, the method used to select the variable entry is the forward LR method. The results are shown in Table 1.

Table 1 Multivariate Analysis Results

\begin{tabular}{|ll|r|r|r|}
\hline & \multicolumn{1}{|c|}{ Scores } & df & \multicolumn{1}{c|}{ Sig. } \\
\hline variable & age & 1.735 & 4 & .784 \\
& sex & 2.107 & 1 & .147 \\
& education & 16.084 & 4 & .003 \\
health status & 7.305 & 4 & .121 \\
marital status & 18.140 & 3 & .000 \\
children & .761 & 2 & .684 \\
living conditions & 7.452 & 2 & .024 \\
family relationships & 7.098 & 3 & .069 \\
family income & 7.778 & 3 & .051 \\
children's visit & 6.827 & 6 & .337 \\
Total statistic & 62.243 & 32 & .001 \\
\hline
\end{tabular}


From the regression results, the level of education, marital status, living conditions have a significant impact on the choice of pension institutions, family income is relatively significant. The specific explanation is as follows:

\section{The Degree of Education Has a Significant Impact on the Wishes.}

From the survey results, the elderly which the education level in high school and above, the choice of pension institutions accounted for $21.97 \%$, higher than the junior high school and below (13.9\%). The higher the education level, the stronger the willingness to stay in pension Institutions. The reason maybe that they are more open in thought, more receptive to new things, so the expectations of the pension institutions higher.

\section{The Marital Status Has a Significant Impact on the Wishes.}

Unmarried, divorced or widowed elderly people choose pension institutions accounted for $21.7 \%$, higher than the spouse of the elderly (13.3\%). Spouse-free elderly people are more likely to choose institutions than others. Whether domestic or foreign, most of the elderly in their own ability to take care of themselves or sick situation, the first depends on the spouse's care, followed by children. Therefore, these lifelong unmarried, divorced or widowed elderly have stronger willingness to stay in the pension institutions.

\section{The Living Situation Has a Significant Impact on the Wishes.}

The elderly living alone choose pension institutions accounted for $24.3 \%$, which was higher than that of the elderly living with spouse or child(13.8\% and $13.7 \%$ respectively), and the impact was similar as the marital status. The elderly living alone had a stronger willingness to stay in the pension agency.

\section{The Family Income Has Relatively Significant Impact on the Wishes.}

The elderly whose family monthly income more than $¥ 9,000$, the choice of pension institutions is $33.3 \%$, significantly higher than the monthly income below $¥ 3000(14.4 \%)$. High income of the elderly are more inclined to institutional pension, compared to family pension, pension institutions can enjoy more professional facilities and the corresponding services.

\section{The Development of Pension Institutions in Hangzhou}

\section{The Number of Pension Institutions is Small}

By the end of 2015, Hangzhou has established a total of 316 pension institutions, including 31 public pension institutions, 134 private pension institutions, 151 township (street) homes for the elderly. The number of beds in the city's pension institutions is 61,900 , with an average of 4.04 beds per 100 elderly people, and there is a gap between 7\% in developed countries. From the number of people living in pension institutions, now 2.64 million people live in pension institutions, only $1.75 \%$ of the elderly population, which and the Hangzhou Municipal Government put forward the "9064" pension pattern in the pension institutions concentrated pension accounted for the proportion of the elderly population reached $4 \%$ Compared to the target, there is a big gap.

\section{Different Kinds of Pension Institutions Development Unbalanced}

Public pension institutions, "a bed is hard to find", while the private pension institutions are "bed vacant". As the public pension institutions in the land, capital and other aspects are more adequate and concessions, so the investment in the environment and facilities than most private institutions. The private pension institutions because it is business-led, in the land, facilities and other inputs without government support, lack of funds, often relatively small scale, facilities are scarce, many institutions are lack of large-scale medical care, activities and other places. So many elderly people do not want to stay in private pension institutions, so that the private pension institutions occupancy rate is low, the profit situation is not ideal, which in turn led to private pension institutions do not have sufficient follow-up funds to improve the facilities, forming a vicious circle.

Take the Second Social Welfare in Hangzhou for example, the elderly monthly cost is about 
$¥ 1,500$, district-level pension institutions double bed fee is lower. In contrast, living in the same grade of private pension institutions should spend $¥ 2,000$ a month at least. From 2013 to 2015 , private pension institutions beds far greater than the total number of elderly people at the end of the year, the majority of the main urban private pension institutions occupancy rate of about $60 \%$ Beds were vacant, faced with varying degrees of losses, hit private capital into the industry.

\section{Lack of Institutional Functions and Facilities}

The function orientation of the pension institution is lack of overall planning and reasonable layout, and most of them are pure support type. However, the pension institution, which integrates the adoption, treatment, rehabilitation, education and entertainment, is developing slowly and with less quantity, especially the lack of special care for the elderly poor self-care ability, disabled medical care institutions. The vast majority of pension institutions lack of infectious diseases, Alzheimer's, mental illness, severe illness patients pension facilities. According to the domestic survey, the prevalence of severe mental illness in the country accounts for about $1.07 \%$ of the elderly population, the incidence of dementia accounted for $5 \%$ to $10 \%$ of the elderly population. Caring for the mentally ill and the elderly with dementia has become a serious burden for many families. However, there are very few institutions for the treatment of Alzheimer's disease in Hangzhou, for the long-term care of the elderly mental illness, rehabilitation services are also facing varying degrees of difficulties.

\section{The Old Service Staff Structure is Irrational, Low Level of Specialization}

According to the experience of Western developed countries, every five elderly people with a service staff is more appropriate, but from our investigation, not only a serious shortage of staff, the structure is not reasonable, there are, for example, too many women, too many old people, low level of specialization. In the face of the rapid development of the economy in Zhejiang Province, for the growing number of retired veterans, old teachers and elderly individual industrial and commercial households such as a large high-income groups, their quality of life requirements are getting higher and higher, so the pension service team needs more open thinking, there are bold, high-quality professional practitioners.

\section{Conclusion}

A. To strengthen government regulation, to establish a diversified development system

The government should encourage social organizations, enterprises, non-governmental organizations or individuals to invest in the pension business by increasing the preferential tax and preferential treatment and increasing the subsidy. The government encourages the development mode of "public private" and "private public assistance". At the same time, we should also strengthen our supervisory functions to ensure the service level and quality of private pension institutions, and do the role of supervisors in the development of the pension business.

B. Rational planning of private pension institutions layout and scale

To establish private pension institutions are mostly enterprises self-behavior, enterprises often considerate of the investment, payback period, yield and other aspects to determine the provision of pension facilities and services provided, rather than from the elderly pension demand perspective. In addition, the current private pension institutions in Hangzhou market segments are not obvious, therefore, the government should rationally plan the layout and scale of private pension institutions, increase government subsidies, according to the needs of the elderly care, respectively, planning different types of pension institutions.

C. To establish a strong sense of responsibility, high-quality pension management and service personnel

Civil affairs departments should be engaged in pre-job training staff, certificates, regular assessment and accreditation mechanism to ensure that the services of the elderly professional and standardized. At the same time, to improve the management and service personnel's ideology and 
professional ethics to serve the elderly better.

D. Pay attention to the propaganda work of social pension

Through the news media and other forms of publicity, advocate a new, healthy concept of old age, and enhance the elderly on the social pension understanding and awareness to eliminate their sense of distrust of the pension institutions, fundamentally change the concept of old age.

\section{Acknowledgement}

The research is supported by the Social-Science Research Project of the Ministry of Education of the People's Republic of China (15YJCZH134), and The key research center of philosophy and social science of Zhejiang province, Zhejiang Technological Innovation and Enterprise Internationalization Research Center.

\section{References}

[1] Gao Xiaolu, Preference of the Urban Elderly for Caring Facilities: Variation across Different Communities, Chinese Soft Science, 2013(1)

[2] Sun Xiaoya, Analysis and Countermeasures on the Aged Demand of Social Institutions in the Period of Economic Transition, Chinese Journal of Gerontology, 2013(7)

[3] Liang Guoqiang, The Current Situation and Influencing Factors of the Elderly in the Old - age Care Institutions, China Public Health Administration, 2014(4) 